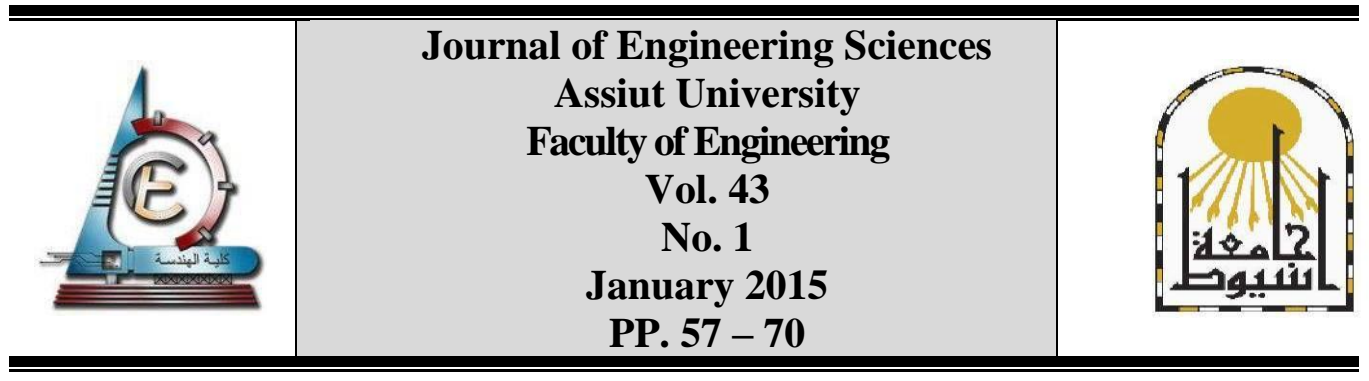

\title{
PRACTICAL APPLICATION OF STOCHASTIC METHODS IN GEOTECHNICAL ENGINEERING
}

\author{
Wael Rashad Elrawy Abdellah \\ Mining \& Metallurgical Eng. Dept., Faculty of Engineering-University of Assiut, Assiut, Egypt \\ Email address: wre544@gmail.com \& waelabdellah@aun.edu.eg
}

(Received 7 January 2015; Accepted 7 February 2015)

\begin{abstract}
Mine haulage drifts are the only stope access in sub-level stoping mining system. Thus, they must remain stable during their service life. Haulage drift instability could lead to serious consequences such as: production delay, damage to equipment, loss of reserves and high operational cost. The goal of this paper is the performance stability evaluation of mine haulage drifts with respect to mining sequence adopting different stochastic methods of analysis. A two-dimensional, elastoplastic, finite difference code (FLAC 2D) is used for this study. Stochastic analysis; adopting Point-Estimate Methods (PEMs), Monte-Carlo Simulation (MCS) and Random Monte-Carlo Simulation (RMCS) are then employed with the numerical modelling to tackle the inherent uncertainty associated with rockmass properties. Then, the probability of instability at last mining step (e.g., after excavating stope 3 ) is estimated for haulage drift side walls and roof. The stability indicators are defined in terms of displacement, stress and the extent of yield zones, which are adopted as a basis for assessing the performance stability of haulage drift. The stochastic results are presented and compared in terms of probability of occurrence at last mining stage (e.g., after excavating stope 3 ) adopting displacement/convergence criterion.
\end{abstract}

Keywords: Probabilistic Methods- Failure Evaluation Criteria- Probability of Instability.

\section{Introduction}

Haulage drifts are the only access where loaders and/or trucks travel through, they must remain stable during their service life. Mine haulage drift instability can result in production delays, loss of reserves, as well as damage to equipment, and injuries. High stress levels can occur in hard rock masses as well as in soft or fractured rockmasses and can lead to unstable state of deformation around deep large excavations [1, 2, and 3].

A recent study by [3] has revealed that as mining activity progresses, it causes continuous stress redistribution around the haulage drift; thus increasing the potential for ground failure. The severity of stress changes were shown to depend on a number of critical parameters such as the quality of the rock mass and the proximity of the mine drifts to the orebody where mining activity takes place. Other parameters that could play an equally important role are the size, dip and depth of the orebody. If failure occurs, the drift becomes dysfunctional and is closed for rehabilitation work. Thus, it can be said that as the extraction of ore progresses in a 
planned sequence of stopes or mining blocks, the stability of nearby mine haulage drifts will continue to deteriorate.

Uncertainty and variability govern the geomechanical data collected from the natural environment. Thus, a reliable design approach must be able to consider uncertainties, to evaluate the probability of occurrence for a system and to take measures to reduce the risk to an acceptable level. Reducing the risk can involve the narrowing of the uncertainty range (e.g., collection of additional data). In order to assess the effect of uncertainty, one needs probabilistic tools that allow the propagation of the uncertainty from the input parameters (e.g., rockmass strength, Young's modulus) to the design criteria (e.g., deformations, stresses, extent of yield zones, strength-to-stress ratio).

In this paper, a simple stepwise methodology, which integrates numerical modelling with probabilistic analysis to evaluate the stability of mine haulage drift with respect to mining activities, is presented. The different probabilistic methods of analyses which are used in this study will be discussed in the next section.

\section{Stochastic methods}

To characterize the uncertainties in the geotechnical rock properties, the engineers need to combine actual data with knowledge about the quality of the data, and the geology. In order to develop a reliable design approach, one must use methods that incorporate the statistics of the input parameters (means, variances, and standard deviations) and the design criteria. The most commonly used methods are the following: Point-Estimate Methods (PEMs), MonteCarlo Simulation (MCS), and Random Monte-Carlo Simulation (RMCS). Each has its advantages and shortcomings [4-13].

\subsection{Point-estimate methods (PEMs)}

Point-estimate method has widely been used in geotechnical reliability analysis for approximating low-order moments of random variables. It is a special case of numerical quadrature based on orthogonal polynomials. The PEMs provide approximations for the low-order moments of the dependent variable Y starting from the low-order moments of the independent variable $X$. For the function $Y=g(x)$, the random variable $X$ could represent rock properties and $\mathrm{Y}$ could be a factor of safety or performance function among other outputs [14].

The PEMs require the mean and variance to define the input variables. In order to determine a probability of "failure", where the term "failure" has a very general meaning here as it may indicate collapse of a structure or in a general form define the loss of serviceability or unsatisfactory performance associated with the performance function $\mathrm{G}(\mathrm{X})[12]$. The performance function $\mathrm{G}(\mathrm{X})$ can be defined as:

$$
\mathrm{G}(\mathrm{X})=\mathrm{R}(\mathrm{X})-\mathrm{S}(\mathrm{X})
$$

Where $\mathrm{R}(\mathrm{X})$ is the "resistance", $\mathrm{S}(\mathrm{X})$ is the "action", and $\mathrm{X}$ is the collection of random input parameters. The failure is implied for $\mathrm{G}(\mathrm{X})<0$, while $\mathrm{G}(\mathrm{X})>0$ means stable behavior. The boundary is defined by $G(X)=0$ separating the stable and unstable state is called the limit state boundary. The probability of failure $\mathrm{P} f$ is defined as (see Figure 1 below):

$$
\mathrm{P} f=\mathrm{P}[\mathrm{G}(\mathrm{X}) \leq 0]=\int_{\mathrm{G}(\mathrm{X}) \leq 0} f(\mathrm{X}) \mathrm{dx}
$$


Where: $f(\mathrm{X})$ is the probability density function of the vector formed by the variables $(\mathrm{X})$.

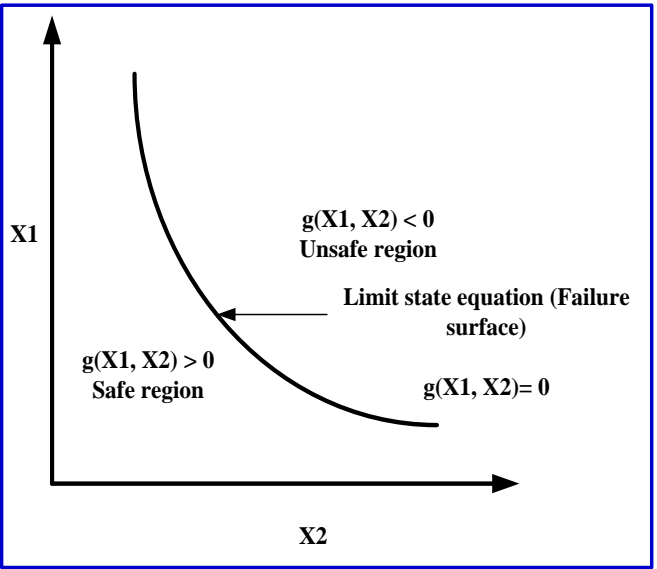

Fig. 1. Limit state concept [15]

\subsection{Monte-Carlo simulation (MCS)}

The Monte-Carlo simulation (MCS) technique is considered as a very powerful tool for engineers with only a basic working knowledge of probability and statistics for evaluating the risk or reliability of complicated engineering systems [15]. A wide range of engineering and scientific disciplines use methods based on randomized input variables "Monte-Carlo Simulation". The MCS method can be quite accurate if enough simulations are performed. In the MCS method, samples of probabilistic input variables are generated and their random combinations used to perform a number of deterministic computations [11]. The MCS consists of sampling a set of properties for the materials from their joint probability distribution function (PDF) and introducing them in the model. A set of results (displacements, strains and stresses) can then be obtained. This operation is repeated a large number of times and an empirical frequency-based probability distribution can be defined for each result. Information on the distribution and moments of the response variable is then obtained from the resulting simulations [16].

The MCS method can be used on existing deterministic programs without modifications. As a result they are popular for probabilistic analysis. Like PEMs, they allow for multiple response functions in a single model. The essential elements that are forming the Monte-Carlo Simulation (MCS) technique have been illustrated by [15] as follows:

- Defining the problem in terms of all random variables;

- Quantifying the probabilistic characteristics of all the random variables and the corresponding parameters;

- Generating the values of these random variables (see Figure 2 below);

- Evaluating the problem deterministically for each set of realizations of all the random variables;

- Extracting probabilistic information from N such realizations; and

- Determine the accuracy and efficiency of the simulation. 


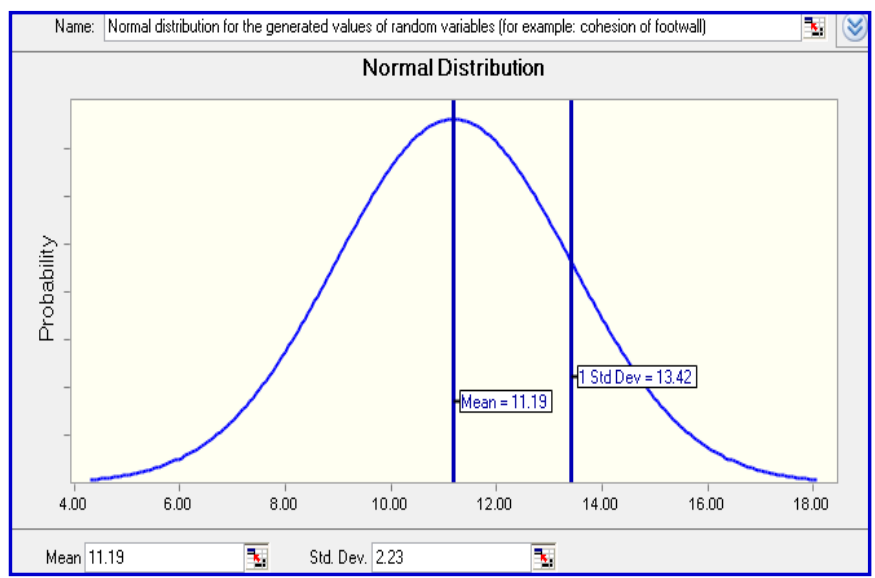

Fig. 2. Normal distribution for the generated values of random variable (for cohesion of rock mass)

Note that the MCS technique can be used for both correlated and uncorrelated random variables. The accuracy of the MCS technique increases with the increase in the number of simulations $\mathrm{N}$. However this can be disadvantageous as it becomes computationally expensive, and as such the simulator's task is to increase the efficiency of the simulation by expediting the execution and minimizing the computer storage requirements [15]. On the other hand, advantages of the MCS include:

- Flexibility in incorporating a wide variety of probability distributions without much approximation, and

- Ability to readily model correlations among variables.

The applications of the Monte-Carlo simulation (MCS) technique are many; such as studying the stability of mine haulage drift by varying the material properties of the footwall. Hence, the chosen stochastic input variables (e.g. cohesion) will assume a distribution from which the material properties of the footwall are assigned. As a result, the output of interest from the MCS runs will be recorded and fitted into a distribution that will provide the probability of failure.

\subsection{Random Monte-Carlo simulation (RMCS)}

The RMCS technique is used to define the unsatisfactory performance of mine developments such as haulage drift stability, and cross-cuts. Means and standard deviations are used to define the input parameter ranges, and then random values from a normal distribution are selected. This includes varying the material properties spatially within the same region; for example, varying the bulk and shear moduli and cohesion properties spatially within the footwall by randomly assigning values from a defined distribution to zones within the region. Therefore, the input values are different in each zone for a given simulation as shown in Figure 3.

One of the primary goals of RMCS is to estimate means, variances and the probabilities associated with the response of the system to the input random seed. The essential elements of RMC technique can be summarized as follows: define mean and standard deviation of the stochastic variable, pick random values of the variable from a normal distribution, assign these values on the FLAC grid at random, generate new initial seed 
values for each new run, fit the results from multiple simulations to a known probabilistic distribution. Calculating the probability of unsatisfactory performance $\mathrm{P}_{f}$ based on a specified condition, e.g. a failure criterion. RMCS deals with spatial uncertainty at the local level, whereas the MCS addresses uncertainty at the global level. RMCS has successfully been applied in seepage analysis, mine pillar stability and slope stability analysis. The required number of simulations with RMC is significantly less compared with Regular Monte-Carlo simulation (MCS) [1, 17].

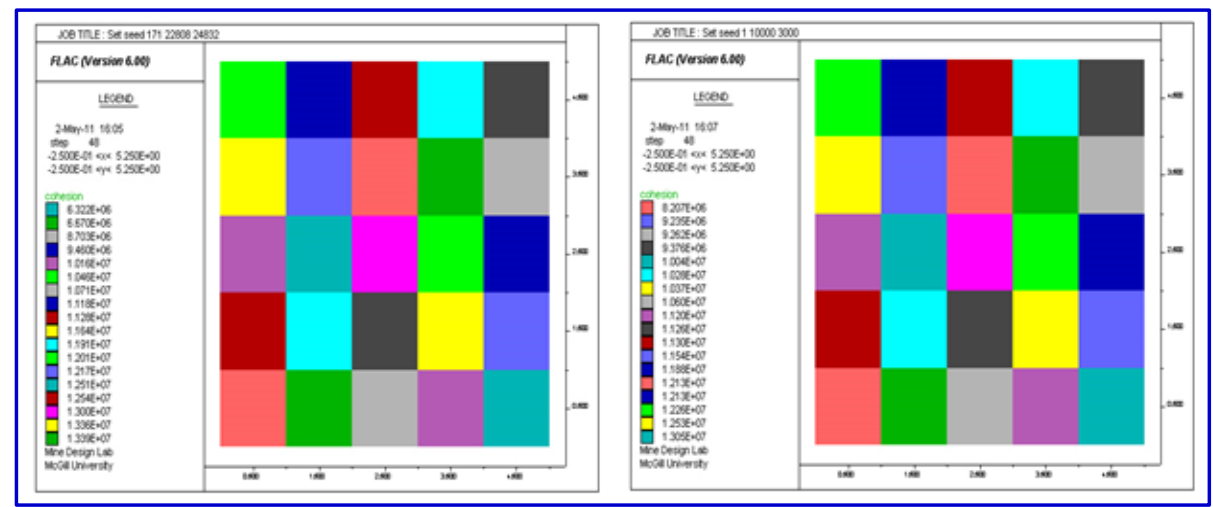

Fig. 3. Spatial variations of bulk and shear moduli and cohesion of rockmass at different random seed (FLAC output) [1].

\section{Performance evaluation criteria}

Although there may be many other aspects to consider when evaluating the performance of mine haulage drift such as: deformation/displacement, mining- induced stress and extent of yield zones. In this investigation only a single condition; deformation/displacement; is considered and compared with different probabilistic methods. A wall convergence ratio (WCR) of $1.50 \%$ and roof sag ratio (RSR) of $0.50 \%$ are adopted as the minimum ratios required for "satisfactory performance" of the mine opening. Thus the probability of unsatisfactory performance of the mine haulage drift is determined accordingly. Any deviation from the satisfactory performance criterion is thus classified to be a failure condition, i.e. when the WCR ratio $>1.5 \%$ and RSR $>0.50 \%$. The deterministic analyses show the numerical modelling results in terms of displacement, mining-induced stress and extent of yield zones. However, stochastic methods of analyses show and compare only displacement with respect to mining step.

\subsection{Wall convergence ratio (WCR)}

WCR is defined as the ratio of the total magnitude of the wall closure to the span of the initial drift as shown in Equation (3) [3]:

$$
\mathrm{WCR}=\frac{\mathrm{W}_{0}-\mathrm{W}_{1}}{\mathrm{~W}_{0}} \times 100 \%=\frac{\Delta_{\max }}{\mathrm{W}_{0}} \times 100 \%
$$

Where:

$W_{0}$ is the original span of the drift and $W_{1}$ : is the span of the drift after deformation. The performance of mine haulage drift will be considered unstable/unsatisfactory if: $G(X)$ $<0$ for all $\mathrm{WCR}>1.5 \%$ and stable/satisfactory if: $\mathrm{G}(\mathrm{X}) \geq 0$ for all $\mathrm{WCR} \leq 1.5 \%$. 


\subsection{Roof sag ratio (RSR)}

RSR is defined as the ratio of the roof sag $(\Delta \mathrm{S})$ to the span of the drift as given in Equation (4) [3]:

$$
\mathrm{RSR}=\frac{\Delta \mathrm{S}}{\mathrm{W}_{0}} \times 100 \%
$$

Where:

$W_{0}$ is the original span of the drift and $\Delta \mathrm{S}$ : is the roof sag. The performance of mine haulage drift will be considered unstable/unsatisfactory if: $\mathrm{G}(\mathrm{X})<0$ for all RSR $>0.50 \%$ and stable/satisfactory if: $\mathrm{G}(\mathrm{X}) \geq 0$ for all $\mathrm{RSR} \leq 0.50 \%$.

\section{Numerical modelling set up}

Numerical modeling is performed using Itasca's FLAC2D software [18]. The mean values for all rock mass parameters are used in the deterministic analysis (Table 1). To examine the stability of mine haulage drift, a typical sectional model is built using FLAC2D software as shown in Figure 4. The studied zone is divided into three areas; hanging wall, orebody and footwall. The orebody consists of massive sulphide rock (MASU). The hanging wall contains Metasediments (MTSD) and the footwall comprises of Greenstone rock (GS). The haulage drift is driven in the footwall parallel to the orebody for the length of its strike (approximately $200 \mathrm{~m}$ long) with cross section dimensions of $5 \mathrm{~m}$ by $5 \mathrm{~m}$ with a slightly arched roof. The thickness of the orebody is $30 \mathrm{~m}$ and the haulage drift is situated at $1500 \mathrm{~m}$ below ground surface and at $25 \mathrm{~m}$ apart from the nearest orebody (e.g., stope 3 ).

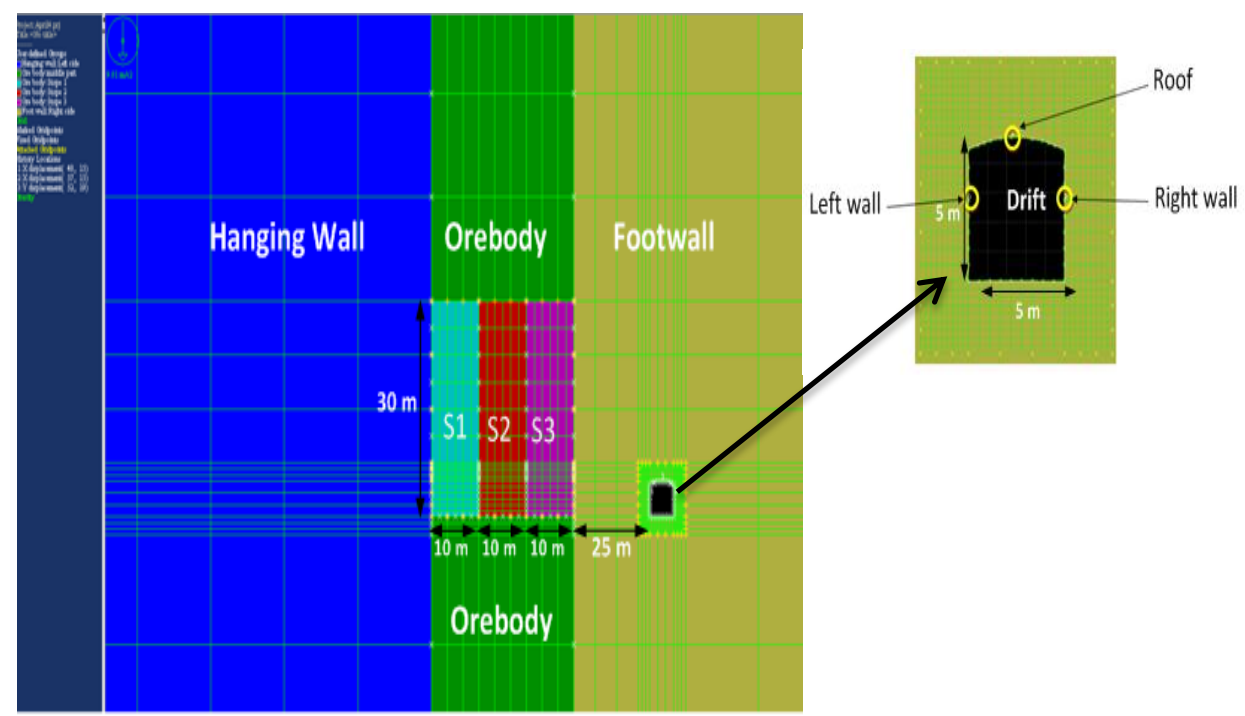

Fig. 4. Model set up and geometry 
Wael Abdellah, Practical application of stochastic methods in geotechnical engineering

Rock mass properties and backfill mechanical properties are listed in Table 1.

Table 1.

Geotechnical properties of the modelled case study

\begin{tabular}{|l|c|c|c|c|}
\hline \multirow{2}{*}{ Rockmass property } & \multicolumn{3}{|c|}{ Domain } & \multirow{2}{*}{ Backfill } \\
\cline { 2 - 4 } & Hanging wall & Orebody & Footwall & \\
\hline Density $\left(\mathrm{kg} / \mathrm{m}^{3}\right)$ & 2782 & 4531 & 2916 & 2000 \\
$\mathrm{UCS}(\mathrm{MPa})$ & 90 & 90 & 172 & 3 \\
$\mathrm{E}(\mathrm{GPa})$ & 25 & 20 & 40 & 0.1 \\
Poisson's ratio, $\vartheta$ & 0.25 & 0.26 & 0.18 & 0.3 \\
Cohesion, C $(\mathrm{MPa})$ & 4.8 & 10.2 & 14.13 & 1 \\
Tensile strength, $\sigma_{\mathrm{t}},(\mathrm{MPa})$ & 0.11 & 0.31 & 1.52 & 0.01 \\
Friction angle, $\phi(\mathrm{deg})$ & 38 & 43 & 42.5 & 30 \\
Dilation angle, $\Psi(\mathrm{deg})$ & 9 & 11 & 10.6 & 0 \\
\hline
\end{tabular}

\section{Stochastic results}

As stated beforehand, there is inherent uncertainty associated with rock mass properties. Hence, one should use a robust tool to tackle these variability and uncertainty in the model input parameters. In this study, only footwall rock mass input parameters are stochastically investigated (e.g., as the mine haulage drift is excavated into footwall rock mass). Three footwall rock mass input parameters are randomly varied based on the pre-specified coefficient of variation (e.g., $\mathrm{COV}=20 \%$ ). These parameters namely are: Young's Modulus, cohesion and friction angle as listed in Table 2. Three main probabilistic methods are invoked with the numerical modelling as shown in Table 3 .

Table 2.

Stochastic model input parameters of footwall rock mass

\begin{tabular}{|l|c|c|c|}
\hline Rock mass Property (Footwall) & Mean & S.D. & COV. \\
\hline Elastic Modulus, E (GPa) & 40 & 8 & $20 \%$ \\
\hline Cohesion, C (MPa) & 11.2 & 2.24 & $20 \%$ \\
\hline Friction Angle, $\phi($ deg.) & 50 & 10 & $20 \%$ \\
\hline
\end{tabular}

Table 3.

Stochastic methods used in this study

\begin{tabular}{|l|l|l|}
\hline \multicolumn{2}{|c|}{ Probabilistic methods } & \multicolumn{1}{c|}{$\begin{array}{c}\text { Number of } \\
\text { simulations }\end{array}$} \\
\hline \multirow{2}{*}{ 1. PEMs } & - Rosenblueth's PEM (2n) & $2^{3}=8$ runs \\
\cline { 2 - 3 } & $\begin{array}{l}\text { Zhou \& Nowak's PEM }\left(2 \mathrm{n}^{2}+1\right. \\
{[19]}\end{array}$ & $2 \times 3^{2}+1=19$ runs \\
\cline { 2 - 3 } & - Li's PEM (n3) & $3^{3}=27$ runs \\
\hline 2. Monte-Carlo Simulation (MCS) & 100 runs \\
\hline 3. Random Monte-Carlo Simulation (RMCS) & 100 runs \\
\hline
\end{tabular}

The stochastic results, for the different probabilistic methods, will be introduced and compared only in terms of displacement/convergence (e.g., section: 5.1).

It can be shown from Figure 5 that, each probabilistic method gives different distribution and therefore, different output for the mean value of the random input variables. Consequently, different probabilities of instability of haulage drift. 
Figure 6 gives the average values for the stochastic input parameters after certain number of simulations.

The calculations of probability of failure (using Z-Table) are given in Table 4 based on equation 5. Probability of instability performance of mine haulage drift at threshold of $1.5 \%$ is shown in Figure 7.

$\mathrm{Z}^{*}=\frac{\mathrm{X}-\mu}{\sigma}$

Where:

$\mathrm{Z}^{*}$ : standard normal variate (represents the area under the PDF curve),

$\mathrm{X}$ : cut-off value (it is taken here as $\mathrm{WCR}=1.5 \%$ ),

$\mu$ : Average value of the output random variable (obtained from PDF distribution) and

$\sigma:$ Standard deviation (obtained from PDF distribution).

\subsection{Wall convergence ratio (WCR)}

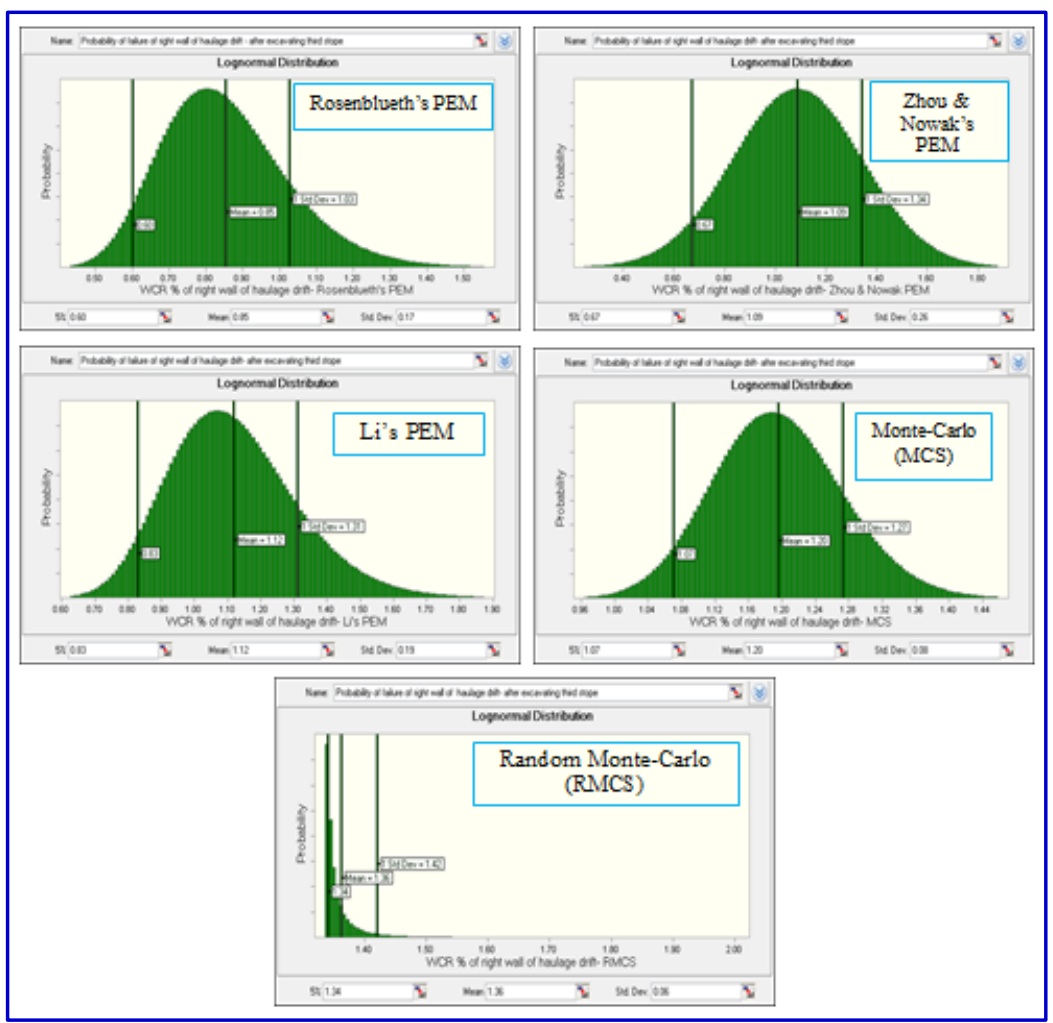

Fig. 5. Probability density function (PDF) for wall convergence ratio (WCR) for each stochastic method at mining step 6 (e.g., after excavating stope 3 ) 


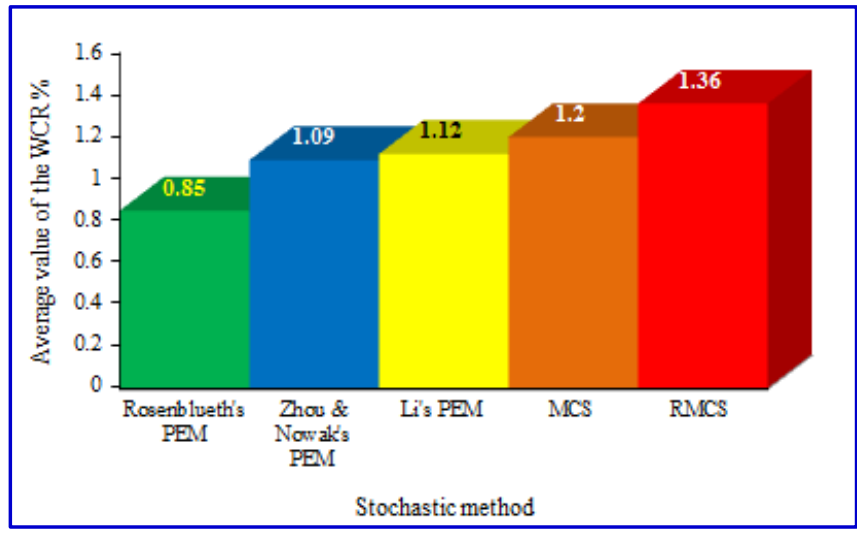

Fig. 6. Average values of $\mathrm{WCR} \%$ at various stochastic methods at mining step 6 (e.g., after excavating stope 3)

\section{Table 4.}

Calculations of the standard normal variate and probability of failure for each probabilistic method

\begin{tabular}{|c|c|c|c|c|c|c|}
\hline \multicolumn{2}{|c|}{ Probabilistic methods } & \multicolumn{2}{|c|}{ WCR \% } & $\mathrm{Z}^{*}=\frac{X-\mu}{\sigma}$ & $\begin{array}{l}\text { Area under } \\
\text { PDF curve } \\
\text { (A) }\end{array}$ & $\begin{array}{c}\mathrm{P} f, \% \\
=(1-\mathrm{A}) \times 100\end{array}$ \\
\hline \multirow[t]{3}{*}{ PEMs } & $\begin{array}{l}\text { Rosenblueth's } \\
\operatorname{PEM}\left(2^{\mathrm{n}}\right)\end{array}$ & 0.85 & 0.17 & $\frac{1.5-0.85}{0.17}=3.82$ & 0.9999 & $\begin{array}{c}(1-0.9999) \times 100 \\
=0.01 \%\end{array}$ \\
\hline & $\begin{array}{c}\text { Zhou \& } \\
\text { Nowak's PEM } \\
\left(2 n^{2}+1\right)\end{array}$ & 1.09 & 0.26 & $\frac{1.5-1.09}{0.26}=1.58$ & 0.9429 & $\begin{array}{c}(1-0.9429) \times 100 \\
=5.7 \%\end{array}$ \\
\hline & Li’s PEM $\left(n^{3}\right)$ & 1.12 & 0.19 & $\frac{1.5-1.12}{0.19}=2$ & 0.9772 & $\begin{array}{c}(1-0.9772) \times 100 \\
=2.28 \%\end{array}$ \\
\hline \multicolumn{2}{|c|}{$\begin{array}{l}\text { Monte-Carlo } \\
\text { Simulation (MCS) }\end{array}$} & 1.20 & 0.08 & $\frac{1.5-1.20}{0.08}=3.75$ & 0.9999 & $\begin{array}{c}(1-0.9999) \times 100 \\
=0.01 \%\end{array}$ \\
\hline \multicolumn{2}{|c|}{$\begin{array}{l}\text { Random Monte-Carlo } \\
\text { Simulation (RMCS) }\end{array}$} & 1.36 & 0.06 & $\frac{1.5-1.36}{0.06}=2.33$ & 0.9901 & $\begin{array}{l}(1-0.9901) \times 100 \\
\quad=0.99 \%\end{array}$ \\
\hline
\end{tabular}

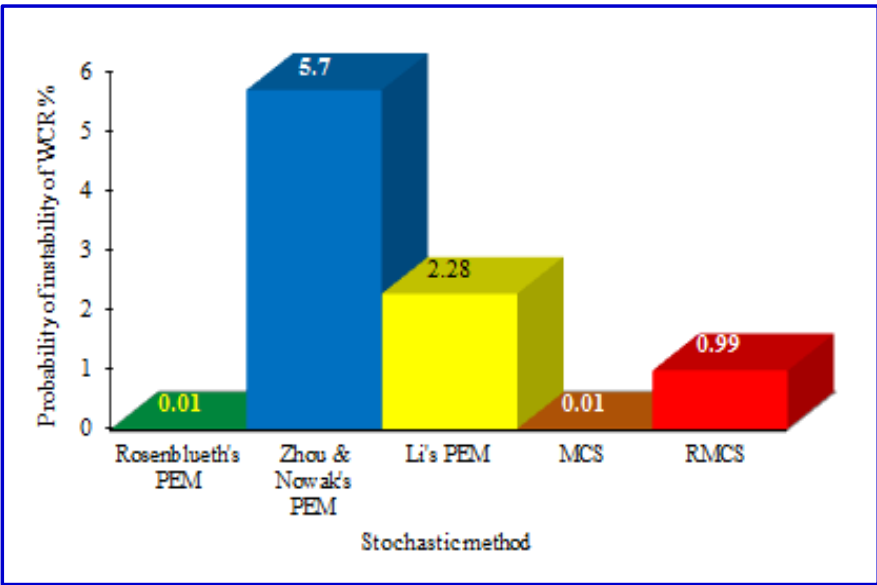

Fig. 7. Probability of instability of WCR \% at various stochastic methods at mining step 6 (e.g., after excavating stope 3 ) 
Table 5, [1], gives the suggested ratings and likelihood of failure. It is obvious that all probabilities of instability of WCR \% with different probabilistic methods are rare (e.g., $\mathrm{P} f<5 \%$ ) except for Zhou \& Nowak's PEM is unlikely (e.g., $\mathrm{P} f>5 \%$ ).

\section{Table 5.}

Suggested ratings and likelihood of failure [1]:

\begin{tabular}{|c|c|c|l|}
\hline Rating & $\begin{array}{c}\text { Likelihood } \\
\text { Ranking }\end{array}$ & \multicolumn{2}{|c|}{ Probability of Occurrence } \\
\hline 1 & Rare & $<5 \%$ & May occur in exceptional circumstances \\
\hline 2 & Unlikely & $5 \%-20 \%$ & Could occur at some time \\
\hline 3 & Possible & $20 \%-60 \%$ & Might occur at some time \\
\hline 4 & Likely & $60 \%-90 \%$ & Will probably occur in most circumstances \\
\hline 5 & Certain & $90 \%-100 \%$ & Expected to occur in most circumstances \\
\hline
\end{tabular}

\subsection{Roof sag ratio (RSR)}
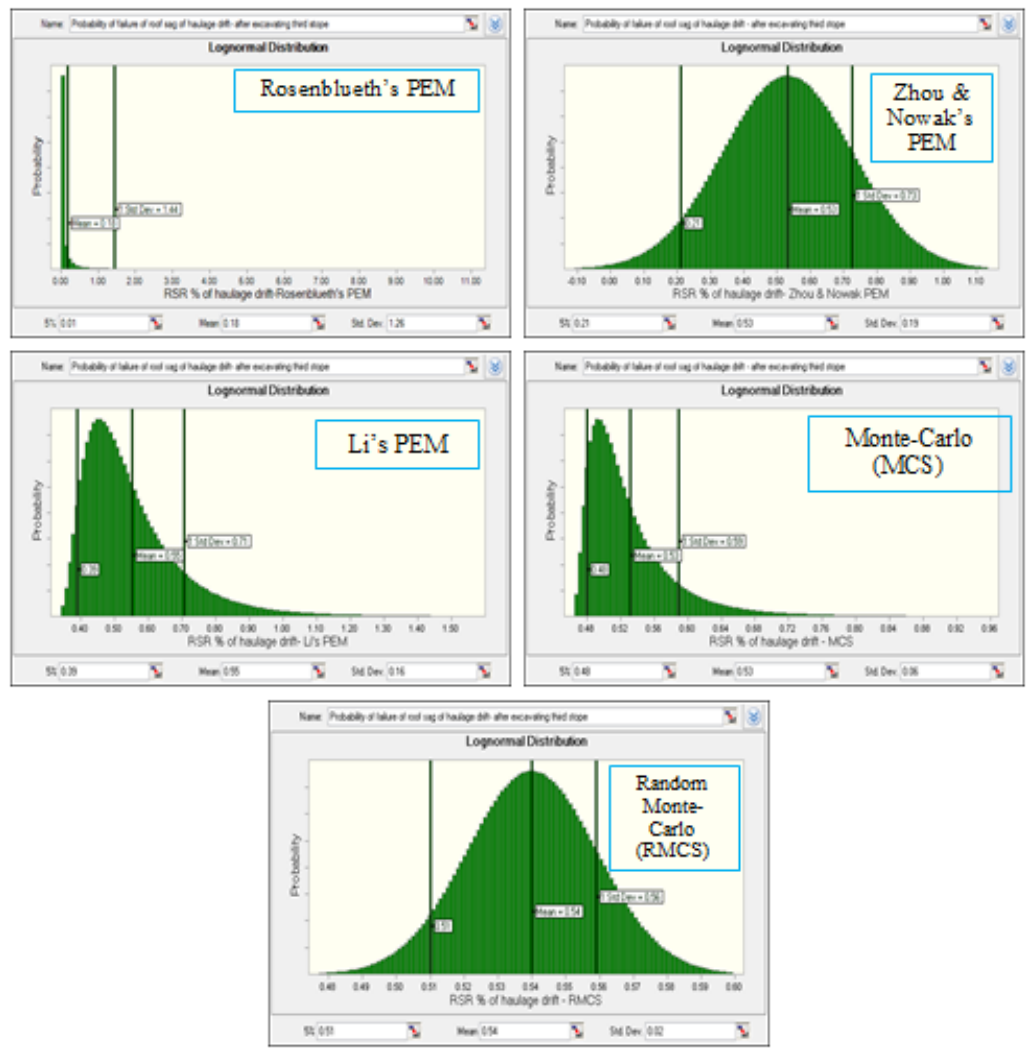

Fig. 8. Probability density function (PDF) for roof sag ratio (RSR) for each stochastic method at mining step 6 (e.g., after excavating stope 3 )

Figure 8 depicts that, each probabilistic method produces different distribution and accordingly, different output for the average values for the random input variables. Consequently, different probabilities of instability of haulage drift. The average values for the random input variables are shown in Figure 9. 


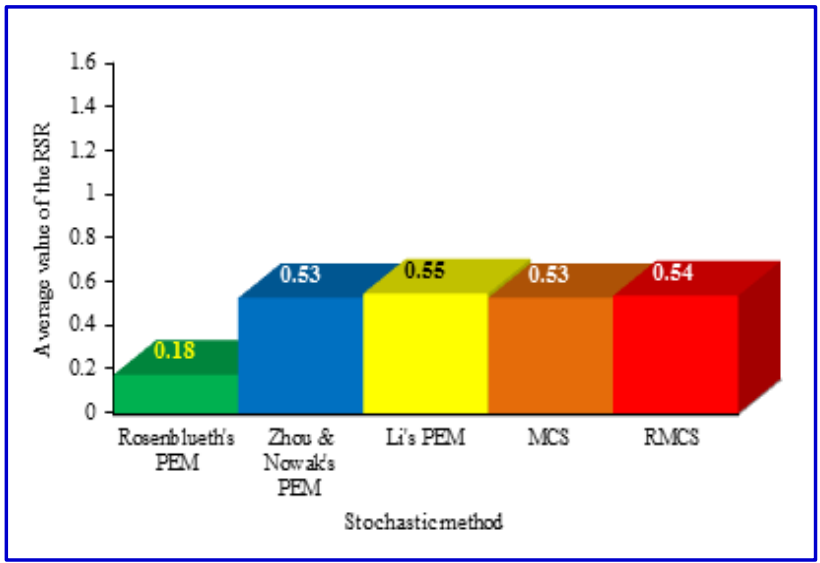

Fig. 9. Average values of RSR \% at various stochastic methods at mining step 6 (e.g., after excavating stope 3 )

Probability of instability is estimated, Table 6, as explained in the previous section using RSR threshold of $0.50 \%$.

Table 6.

Calculations of the probability of instability of RSR at each probabilistic method

\begin{tabular}{|c|c|c|c|c|c|c|}
\hline \multirow{2}{*}{\multicolumn{2}{|c|}{ Probabilistic methods }} & \multicolumn{2}{|c|}{ WCR \% } & \multirow{2}{*}{$\mathrm{Z}^{*}=\frac{X-\mu}{\sigma}$} & \multirow{2}{*}{$\begin{array}{l}\text { Area under } \\
\text { PDF curve } \\
\text { (A) }\end{array}$} & \multirow{2}{*}{$\begin{array}{c}\mathrm{P} f, \% \\
=(1-\mathrm{A}) \times 100\end{array}$} \\
\hline & & $\mu$ & $\sigma$ & & & \\
\hline \multirow{3}{*}{ PEMs } & Rosenblueth's PEM $\left(2^{\mathrm{n}}\right)$ & 0.18 & 1.26 & 0.25 & 0.5987 & 40.13 \\
\hline & Zhou \& Nowak's PEM $\left(2 n^{2}+1\right)$ & 0.53 & 0.19 & -0.16 & 0.5636 & 43.64 \\
\hline & Li's PEM $\left(n^{3}\right)$ & 0.55 & 0.16 & -0.31 & 0.3783 & 62.17 \\
\hline \multicolumn{2}{|c|}{ Monte-Carlo Simulation (MCS) } & 0.53 & 0.06 & -0.5 & 0.3085 & 69.15 \\
\hline \multicolumn{2}{|c|}{$\begin{array}{lll}\text { Random } & \text { Monte-Carlo } & \text { Simulation } \\
\text { (RMCS) }\end{array}$} & 0.54 & 0.02 & -2 & 0.0228 & 97.72 \\
\hline
\end{tabular}

As listed in Table 6, the probabilities of instability due to roof sag adopting Rosenblueth's and Zhou \& Nowak PEMs [19] are possible (e.g., Pf<60\%). Li's PEM and MCS show the probabilities of instability of the drift roof are likely (e.g., Pf $<90 \%$ ). However, the probability of drift roof instability is certain with RMCS (e.g., Pf $>90 \%$ ). The probabilities of instability at each probabilistic method are shown in Figure 10.

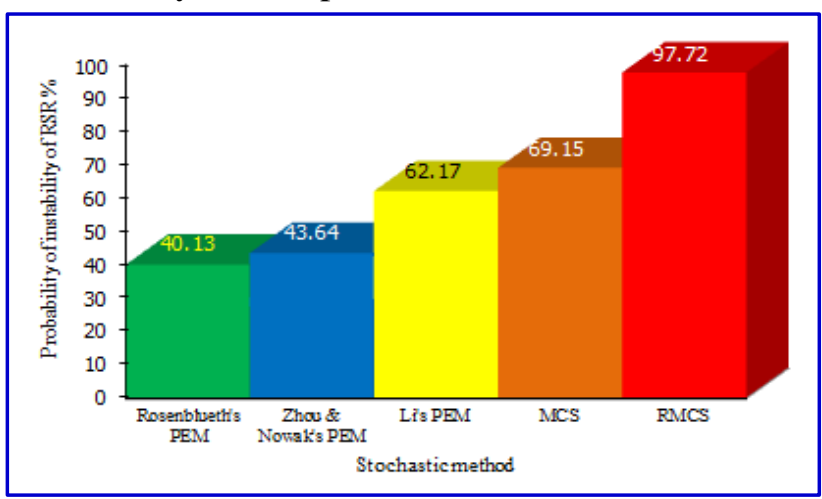

Fig. 10. Probability of instability of RSR \% at various stochastic methods at mining step 6 (e.g., after excavating stope 3 ) 


\section{Conclusion}

The stability of mine haulage drifts is of utmost importance during the planned period of production or the life of a mine plan. Mine drift instability can cause production delay, loss of reserves, as well as damage to equipment and injury to miners. This paper presents a stepwise methodology to assess the stability of mine haulage drifts with respect to mining activity. Two-dimensional elasto plastic, finite difference model (FLAC2D) is constructed to simulate the performance of haulage drift situated $1.5 \mathrm{~km}$ below ground surface. Three different probabilistic methods are adopted in conjunction with finite difference FLAC to tackle the inherent uncertainty associated with footwall rock mass input parameters. Displacement/convergence evaluation criterion is adopted. The probabilities of instability of WCR show insignificant difference with adopted stochastic methods. This may be due to high threshold value (e.g., 1.5\%). Thus, Zhou \& Nowak's PEM is more conservative (e.g., $\mathrm{P} f=5.7 \%)$ comparing to other methods. However, a significant discrepancy in the probabilities of failure of RSR appears and this may attribute to small threshold value (e.g., 0.5\%). Random Monte-Carlo method looks more conservative (e.g., $\mathrm{P} f=97.72 \%$ ). The choice among these probabilistic methods depends on many factors such as: purpose and results accuracy of the analysis, size of the model (e.g., number of elements and zones), number of random input variables, capability of computer (e.g., speed run and storage size for the output files) and knowledge of the modeler (e.g., subroutine, fish codes, etc.).

\section{Recommendation}

Three-dimensional modelling (3-D) is necessary to simulate the real geometry of the case study. In-situ stress measurements should be used to calibrate the numerical model. Model results must be validated based on underground measurements such as deformations (Multi-Point Borehole Extensometer or MPBX) and rockbolt loads.

\section{REFERENCES}

[1] Abdellah, W., H. S. Mitri, et al. (2012). "Stochastic evaluation of haulage drift unsatisfactory performance using random Monte-Carlo simulation." Int. J. Mining and Mineral Engineering 4 (No. 1): 63-87.

[2] Wei, W., H. S. Mitri, et al. (2012). Evaluating Immediate Mining Induced Ground Movement the Performance of the Primary Support System. In Proceedings of $21^{\text {st }}$ Canadian Rock Mechanics Symposium, RockEng12, May 5-9, Edmonton, AB, Canada.

[3] Zhang, Y. and H. S. Mitri (2008). "Elastoplastic stability analysis of mine haulage drift in the vicinity of mined stopes." International Journal of Rock Mechanics and Mining Sciences (IJRMMS) 45: 574-593.

[4] Christian, J. T. and B. G. Baecher (1999). "Point Estimate Method as Numerical Quadrature." Journal of Geotechnical and Geoenvironmental Engineering 125 (9): 779-786.

[5] Christian, J. T. and B. G. Baecher (2002). "The Point Estimate Method with large number of variables." Int. Journal for Numerical and Analytical Methods in Geomechanics. 26 (8): 1515-1529.

[6] Christian, J. T. and B. G. Baecher (2003). Reliability and Statistics in Geotechnical Engineering West Sussex, England, The Atrium, Southern Gate, Chichester, West Sussex, England, John Wiley \& Sons Ltd.

[7] Chang, C.-H., Y.-K. Tung, et al. (1995). "Evaluation of probability point estimate methods." Appl. Math. Modelling Vol.19 (2): 95-105.

[8] Rosenblueth, E. (1975). "Point estimates for probability moments" Proc. Nat. Acad. Sci. Vol. 72, No. 10: 3812-3814.

[9] Rosenblueth, E. (1981). Two- Point Estimates in Probabilities Universidad National Autonoma de Mexico. D. F., Mexico. 20. 
[10] Peschl, G. M. and H. F. Schweiger (2002). Reliability in Geotechnics with Finite ElementsComparison of probabilistic, Stochastic and Fuzzy Set Methods. Graz University of Technology, Austeria: 437-450.

[11] Hammah, R. E., T. E. Yacoub, et al. (2008). Probabilistic slope analysis with the finite element method. American Rock Mechanics Association (ARMA).

[12] Schweiger, H. F. and R. Thurner (2007). "Basic Concept and Applications of Point Estimate Methods in Geotechnical Engineering." 491: 97-112.

[13] Musunuri, A., W. Wei, et al. (2009). Assessment of drift stability using probability of failure. . In Proc Eighteenth International Symposium on Mine Planning and Equipment Selection. A. Mehrotra, F. K. and H. G. eds. Singhal, R.K. Banff, AB: 987-996.

[14] Ang., A. H. S. and Tang, W. H. (1975). "Probability Concepts in Engineering Planning and design", Vol. I., New York, John Wiley \& Sons, 1975.

[15] Haldar, A. and S. Mahadevan (2000). Probability, Reliability, and Statistical Methods in Engineering Design. New York, NY, John Wiley \& Sons, Inc.

[16]Duncan, J. Mellah. (2000). "Factors of Safety and Reliability in Geotechnical Engineering." Journal of Geotechnical and Geoenvironmental Engineering 126(4): 307316.

[17] Abdellah, W., Mitri, H. S., and Thibodeau, D. (2011). "Assessment of Mine Haulage Drift Safety Using Probabilistic Methods of Analysis" Procedia Engineering, Elsevier. 26: 2099 - 2111.

[18] ITASCA (2009). Fast Lagrangian Analysis of Continua in 3 Dimensions (FLAC3D), User's Manual Ver. 4.0 Minnesota 55401 USA, Itasca Consulting Group Inc., Minneapolis.

[19] Jianhua, Z. and S. A. Nowak (1988). "Integration formulas to evaluate functions of random variables." Structural Safety Vol. 5: 267-284. 


\section{التطبيق العملى للطرق الإحصائية فى الهندسة الجيوتقتية}

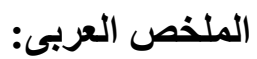

تعتبر ممر ات نقل الخام هى المنفذ الرئيسى والوحيد فى المناجم شديدة العمق. لذا يجب أن تظل هذه الممرات

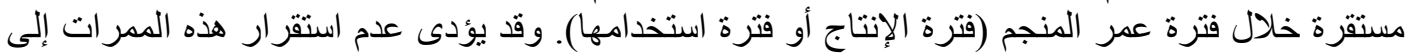

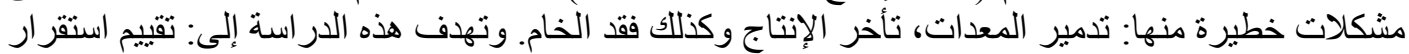

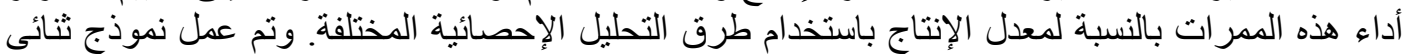

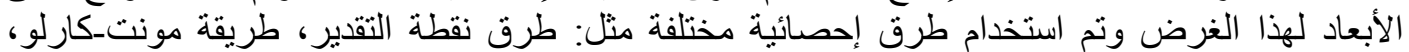

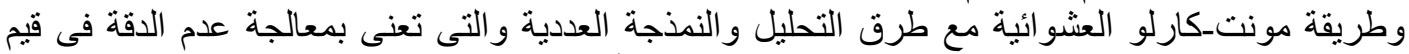

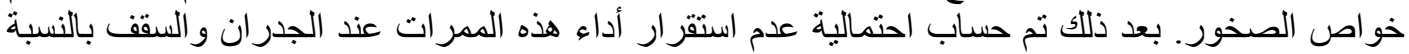
لآخر خطوة انتاج.

الكلمات الرئبيسية: الطرق الإحصائية - وسائل تقييم الانهيار ـ احتمالية عدم الاستقرار. 